\title{
Analysis of Cloud-Based E-government Services Acceptance in Jordan: Challenges and Barriers
}

\author{
Abeer Alkhwaldi ${ }^{1,2, *}$, Mumtaz Kamala ${ }^{1, * *}$, Rami Qahwaji ${ }^{1, * * *}$ \\ ${ }^{1}$ School of Electrical Engineering and Computer Science \\ Bradford University, Bradford, United Kingdome \\ ${ }^{2}$ Department of Management Information Systems, School of Business \\ Mutah University, AlKarak, Jordan
}

\begin{abstract}
There is increasing evidence that the Cloud Computing services have become a strategic direction for governments' IT work by the dawn of the third-millennium. The inevitability of this computing technology has been recognized not only in the developed countries like the UK, USA and Japan, but also in the developing countries like the Middle East region and Malaysia, who have launched migrations towards Cloud platforms for more flexible, open, and collaborative public services. In Jordan, the cloud-based e-government project has been deemed as one of the high priority areas for the government agencies. In spite of its phenomenal evolution, various governmental cloudbased services still facing adoption challenges of egovernment projects like technological, humanaspects, social, and financial which need to be treated and considered carefully by any government agency contemplating its implementation. While there have been extensive efforts to investigate the egovernment adoption from the citizens' perspective using different theories and models, none have paid adequate attention to the security issues. This paper explores the different perspectives of the extent in which these challenges inhibit the acceptance and use of cloud computing in Jordanian public sector. In addition to examining the effect of these challenges on the participants' security perception. The empirical evidence provided a total of 220 valid responses to our online questionnaire from Jordanian citizens including IT- staff from different government sectors. Based on the data analysis some significant challenges were identified. The results can help the policy makers in the public sector to guide successful acceptance and adoption of cloudbased e-government services in Jordan.
\end{abstract}

\section{Introduction}

Development of Information and Communication Technology (ICT) is one of the significant characteristics of our era and, like other innovations, it has an important influence in terms of changing and modernization people life to some extent. Specifically, the evolution of ICT has a dramatic change in citizens' interaction with their governments, significantly developing their expectations in this regard $[1,2]$. With the inception of e-government systems, a number of government organizations worldwide have moved away from the traditional form of public administrations to electronic forms, as they realized the importance of delivering high-quality and more efficient services to its citizens [3, 4]. However, the further utilization of e-government services resulted in more adoption and acceptance challenges like technological and financial ones [4, 5]. Innovative ICT, such as cloud computing technology can contribute to overcome these challenges; cloud computing represents a fundamental change in the technological environment construction of the public sector and the way that governments conduct their business $[6,7]$.

In the past two decades, the governmental sector focused predominantly on the traditional online webbased services to enhance accountability, transparency, and accessibility to public services and information. Led by the pioneering initiatives in many developed countries such as UK, Japan, USA and EU [8, 9], cloud technology made a successful advancement towards being the next-generation of egovernment services. The idea is to utilize ubiquitous, highly scalable, location-independent IT resources to develop organizational processes and reinvent the government services that meet citizens' expectations to improve collaboration between government agencies with more flexible, open, lowcost and unified computing. However, the cloudbased e-government considered as a profound change within governments also represents a usercentric services platform aiming to increase citizens' participation.

In recent years, the public sector in the developing countries, in particular, the Middle East have started gearing towards cloud computing to achieve an increased level of efficiency and performance while offering cost-effective outcome [10]. However, a number of these governments are still in the initial stages of that process. The Hashemite Kingdom of Jordan (HKJ), the country in the heart of Middle East region, is in the process of complete migration to Cloud-Government. Jordan realised the vital role of the Cloud Computing in the e-government context and launched the first 
"National Cloud Platform", designed to achieve continual improvements and growth within the egovernment applications [11]. In these days, a number of government entities and ministries apply cloud-based solutions to provide improved public services to their citizens; however, a high-percentage of Jordanian nationals do not yet use cloud-based egovernment services and still, depend on paper printouts of their official transactions. Accordingly, the services provided based on the cloud computing technology like the "Issuing Certificate of NonCriminal Record" are not exploited effectively.

A number of theories and models of IS/IT acceptance, like Theory of Planned Behavior (TPB), Technology Acceptance Model (TAM) and, the latest developed model, the second version of the Unified Theory of Acceptance and Use of Technology (UTAUT2), have been largely applied to examine the individuals' reluctance or low adoption of new e-government services [12]. However, these theoretical models, including the UTAUT2 itself, are criticized for not considering the constructs depicting the specific perspectives of egovernment (e.g. security). This paper takes a step towards answering the question: "Do the barriers and challenges of e-government adoption influence the use of cloud-based e-government services from the Jordanian citizens' and government's perspective?". The findings of this research verified that some e-government challenges still influence the acceptance of cloud-based public services like the lack of awareness and security. In addition to validating some of the security concerns related to this research context, hence these can be taken into consideration when formulating a new theoretical model.

\section{Challenges of E-Government}

E-government initiatives aim to raise the level of governments' performance while providing the citizens with upgraded public services. However, a number of authors indicate that different types of barriers are faced by government entities which hindered the achieving of e-government promised goals and degraded its successful adoption [8, 13]. Therefore, the public sector has the responsibility to overcome such difficult hurdles. Despite the governments' efforts in this regard, the success of egovernment initiatives is contingent upon citizens' willingness to use and accept the e-government services employing new ICT [3]. Notably, Security is one of the significant causes of hesitation about egovernment services due to lingering perceived security concerns [14].

The most encountered challenges of egovernment acceptance and adoption can be grouped into categories as outlined in Table 1.

\subsection{Technological Challenges}

The e-government initiatives deployment was for a long time restrained by technological issues. For instance, lack of security is a critical obstacle in implementing e-government services according to citizens' concerns [15]. This section illustrates the main barriers face e-government from the technical aspect.

2.1.1. IT infrastructure. Although the going down of IT cost, sufficient IT infrastructure is still considered as one of the most common barriers to egovernment services, also influence citizen adoption of such services $[16,17]$. It composed of networks such as LAN (local area network), WAN network (Extranet, Intranet and Internet), other technical components, databases and operating systems. Creating new communication channels to deliver and share the e-government information and services requires adequate internetworking [17, 18]. Similarly, Ebrahim and Irani (2005) asserted the significance of internetworking capacity as a base for IS integration across the public sector. Also, IT infrastructure could be experienced by lack of software and hardware.

In many developing countries, the poor IT infrastructure often prohibits the successful implementation of e-government. Consequently, governments require supporting a strong IT infrastructure to enable the citizens to benefit from egovernment services.

2.1.2. Security. Security refers to the protection of systems, information, and data against intentional or accidental disclosure, copying and alteration resulting from unauthorized access [19]. A number of studies have identified security as a significant barrier influence the intention to use the egovernment services across the world, and that is from both governments' and citizens' perspective [15-17]. While there is a consensus among the research community that security can have technical or non-technical aspects, the non-technical issues have more influence in the developing countries.

The Perceived information security can be defined as "the subjective probability with which consumers believe that their personal information will not be viewed, stored or manipulated during transit or storage by inappropriate parties, in a manner consistent with their confident expectations" [20]. So, perceived security is an essential element to build the trust between the government and its citizens. As stated by Ndou (2004), governments around the globe need to secure the transactions between the government organizations and individuals. 
2.1.3. Availability. The development any Information System IS like e-government could result in many challenges to the internal and external stakeholders (e.g. availability and accessibility) [17, $21,22]$. It is essential to distinguish between these two terminologies. Availability refers to the number of e-services that are available for the citizens $24 / 7$ [17]. As illustrated by Criado et al. (2003), the vital promises of e-government projects can be achieved by an integration of various factors, for example, accessibility and availability [23]. Moreover, availability improves citizens' satisfaction with of egovernment system due to its pivotal influence on the service quality [24]. By contrast, the scarcity of these two important factors would lead to failure of e-government efforts.

While the above-mentioned discussion points out the availability as a ranking standard for the success and adoption of e-government, accessibility to egovernment services is also crucial.

2.1.4. Accessibility. Accessibility term is used to describe the ways in which citizens' obtain online government services and information through of multiple e-channels $[16,22]$. The presence of such channels makes the service accessible to all types of citizens despite religion, residence place or even disabilities. Alomari et al. [22] proposed the service accessibility as an important predictor to establish "citizen-centric" e-government services.

Thus, the government agencies should ensure the accessibility and availability of their web services to all stakeholders from different locations around the clock. For example, governments could launch free Wi-Fi service within a national strategy to encourage the citizens' participation in e-government services.

2.1.5. Website design. Recently, the governments' websites have emerged as the main gateways for delivering public services to citizens [22, 25]. Research on e-government has found that website design is a significant factor affected citizen's willingness to accept e-government services [22]. Standardized design and well-organized content increase the users' intention to use e-government. In addition, explicit security policies, instructions, and password tips should be ensured in the design of website; due that citizens' use of e-government is a questionable matter without a security guarantee [26].

\subsection{Human Aspects}

"Once the people have the infrastructure to go online, they need the awareness, skills and online content to motivate their access" [27]

The investigation shows that lack of both awareness and IT-skills are the two dominant human-aspects under the barriers to e-government initiatives [18].

2.2.1. Lack of awareness. In general, citizens have limited awareness about e-government services and its benefits [28]. It has been found that the lack of awareness is one of the obstacles to successful adoption of E-government [25, 29]. Awareness refers to the person's understanding of others' activities, which yields to a context for his own activities [25].

Lack of awareness is a basis for low rates of citizens' participation and failure of e-government projects [24]. Therefore, governments should initiate attractive awareness campaigns to promote new egovernment services and to achieve its successful diffusion and implementation.

2.2.2. ICT skills. Two types of skills are required to use e-government systems by citizens. These are: IT literacy and Information security literacy. The dearth of these skills is a crucial challenge to e-government initiatives, particularly in developing countries [30]. IT-Literacy used to indicate the marginalized people who are incapable to use ICT due to the lack of computer knowledge and education [17]. While the information security literacy means the scarcity of basic knowledge about the secure online practices [31].

In fact, the governments needed to provide their citizens with the essential computer, security and internet skills to improve their participation in egovernment. In this regard, Almarabeh and AbuAli [17] emphasized the vital importance of citizens' training, as it prevents the rise of two groups within the society "information poor" and "information rich".

\subsection{Social Challenges}

Social issues to the adoption of e-government are not a technological barrier, but rather hinge on social implications of new IT. The social aspect includes a number of challenges like income, language, culture, education and digital divide. In respect to this study, culture will be clarified.

2.3.1. Culture. The effective implementation and adoption of e-Government services need to overcome the cultural challenges [22, 32]. Culture can be identified by different factors such as people values, beliefs, behaviour and religion. Also, generally it can be classified into three types: organisational culture, national culture, and security culture. In the context of this study, It is important to clarify exactly what is meant by "security culture" which refers to the socio-behaviour and customs of a specific society, that affect their security practices [33]. 
Resistance to change by citizens may lead eventually to negative outcomes regarding egovernment participation [32]. Therefore, it's required from the governments to improve the social life and establish a knowledge-based society in an effort to change IT-culture of their citizens.

\subsection{Financial Challenges}

Even if the public sector has the effective strategies to implement the e-government and to overcome the aforementioned challenges; it can be argued that is not enough to ensure the successful initiatives of e-government. This is owing to the high cost of the maintenance and implementation of the IT systems, which resulted in a funding dilemma of e-government initiatives [34]. Thus, a number of authors have asserted the "lack of financial recourses" as a prominent challenge of e-government $[8,28,29]$, particularly in the developing countries. Also, to avoid the funding barrier, public administrations need to guarantee long-period financial support for the e-government as it is a longterm initiative.

Table 1. Categories of E-Government Adoption Challenges

\begin{tabular}{|c|c|c|}
\hline Challenges & Examples & Ref. \\
\hline \multicolumn{3}{|l|}{ Technological } \\
\hline - IT infrastructure & $\begin{array}{l}\text { - Insufficient networking } \\
\text { capacity } \\
\text { - Inadequate integration across } \\
\text { systems } \\
\text { - Poorly updated } \\
\text { hardware and software } \\
\text { - incompatibility and } \\
\text { complexity of the existing } \\
\text { systems }\end{array}$ & {$[16,30]$} \\
\hline - Security & $\begin{array}{l}\text { - lack of transactions' } \\
\text { protection } \\
\text { - lack of trust in online and } \\
\text { government e-services } \\
\text { - lack of security hardware in } \\
\text { the public sector }\end{array}$ & $\begin{array}{l}{[15-17,} \\
25,30]\end{array}$ \\
\hline - Availability & $\begin{array}{l}\text { - Inability to deliver services } \\
\text { and information upon request } \\
\text { - Slow response to citizens } \\
\text { expectations, making } \\
\text { unsuccessful delivery of the e- } \\
\text { services. }\end{array}$ & {$[24,30]$} \\
\hline - Accessibility & $\begin{array}{l}\text { - Difficulty to access the } \\
\text { system by the people with } \\
\text { disabilities } \\
\text { - Internet coverage is limited }\end{array}$ & {$[30,32]$} \\
\hline - Website design & $\begin{array}{l}\text { - limited languages to present } \\
\text { the website content } \\
\text { - perceived ease of use } \\
\text { - perceived usefulness }\end{array}$ & $\begin{array}{l}{[22,24,} \\
25]\end{array}$ \\
\hline \multicolumn{3}{|l|}{ Human-aspects } \\
\hline $\begin{array}{ll}\text { - Lack } & \text { of } \\
\text { awareness } & \end{array}$ & $\begin{array}{l}\text { - lack of knowledge about e- } \\
\text { government services and its } \\
\text { benefits } \\
\text { - lack of orientation campaigns }\end{array}$ & $\begin{array}{l}{[24,25,} \\
28]\end{array}$ \\
\hline
\end{tabular}

\begin{tabular}{|c|c|c|}
\hline & to promote e-government & \\
\hline - ICT skills & $\begin{array}{l}\text { - Lack of IT skills among users } \\
\text { of e-government (i.e. citizens, } \\
\text { employees, IT staff) } \\
\text { - Lack of baseline knowledge } \\
\text { related to the secure online } \\
\text { practices }\end{array}$ & {$[25,31]$} \\
\hline \multicolumn{3}{|l|}{ Social } \\
\hline - Culture & $\begin{array}{l}\text { - Religious and tribal beliefs } \\
\text { - Language problems } \\
\text { - Change resistance }\end{array}$ & {$[32,35]$} \\
\hline \multicolumn{3}{|l|}{ Financial } \\
\hline $\begin{array}{l}\text { - Lack of budget } \\
\text { / high cost }\end{array}$ & $\begin{array}{l}\text { - High maintenance and } \\
\text { operational cost } \\
\text { - High budget for security } \\
\text { solutions }\end{array}$ & {$[15,16]$} \\
\hline
\end{tabular}

While much of the previous literature has focused on the e-government challenges from different perspectives (i.e. government stakeholders), relatively little has been conducted to examine the impact of these challenges on the adoption and acceptance of cloud-based services in the public sector context. Furthermore, the extent to which these challenges are pertinent to the perceived security of cloud-based e-government services. Consequently, there is a concurrent need to gain an empirical examination for the influence of such challenges on the acceptance and security of cloud computing services and applications in the public sector. In this paper, an online survey was conducted to achieve this study aim.

\section{Cloud Computing}

Cloud Computing has become a significant milestone in the development of Information Systems (IS) and a salient IT strategy for governments, due offering highly-scalable computing resources. According to the definition provided by National Institute of Standards and Technology (NIST), Cloud computing is " a model for enabling ubiquitous, convenient, on-demand network access to a shared pool of configurable computing resources that can be rapidly provisioned and released with minimal management effort or service provider interaction" [36].

Cloud Computing is considered as one of the most promising ITs nowadays, inherently has distinct characteristics include broad network access, ondemand self-service, rapid elasticity, pooled resources, measured service (see Figure 1) [36]. Wang et al. use the term 'cloud computing' to refer to "the delivery of computing as a service rather than a product" [37]. This service is provided to the government agencies, business, and individuals on three different models including Infrastructure as a Service (IaaS), Platform as Service (PaaS), and Software as Service (SaaS). Also, based on the scope of usage, cloud computing can be grouped into four 
deployment models, which are: private cloud, hybrid cloud, community cloud, and public cloud [36, 37]. Security concerns become critical during the delivery of the services and influence user's acceptance and use of such services [38].

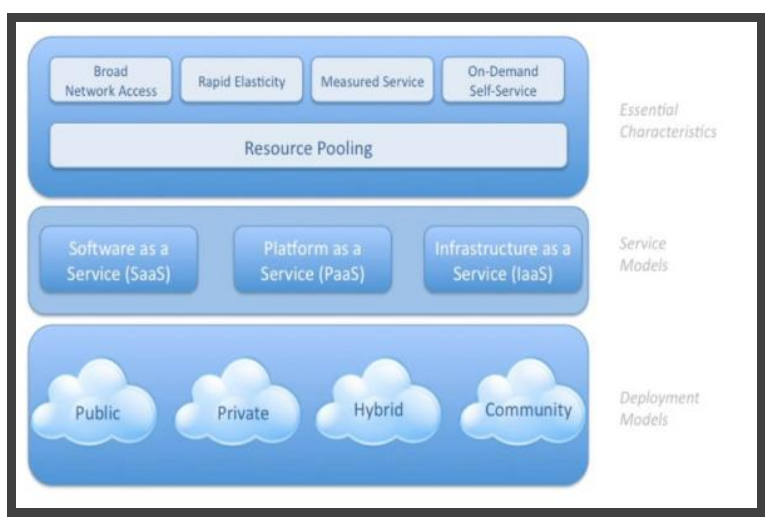

Figure 1. NIST definition of Cloud Computing [36]

\section{Cloud Computing in the E-government Context}

Evidence from previous research shows that cloud technology was adopted as a novel channel for the delivery of public services [39], where significant improvements in the government sector performance, also creating innovative public services were detected across various contexts, worldwide [40]. Around the globe, governments have begun to deliver various services based on the cloud platforms to enhance the services quality, realize efficiency, reduce cost [41, 42]. Harnessing Cloud Computing (CC) to deliver government services provides a number of benefits (e.g. dynamic scalability, accountability, distributed storage, security management, and green IT) [43, 44].

However, there is a high deal of risk, both tangible risk (e.g. availability and infrastructure) and intangible risk (e.g. security) are associated with cloud-based e-government services along with benefits of the cloud applications [7]. Security concerns and relevant issues are the main sources of the risk [45]. Therefore, its required to address and identify such concerns for cloud-based e-government services along with other types of risks. Consequently, governments will have the ability to risk-management of the cloud platforms, which is considered as the main determinant of $\mathrm{CC}$ success and acceptance.

\section{Acceptance and Adoption of New Technology: Theories and Models}

Understanding individual-level of IT acceptance is one of the well-established streams in the area of information system (IS) research [46, 47]. Thus far different competing models and theories have been developed to understand the users' acceptance behaviour of IT/IS. Among these models and theories, the TAM, the TPB, the Theory of Reasoned Action (TRA) and so on [48]. There was a need to create a comprehensive model that provides a more complete picture of the user's IT acceptance process than any previous theoretical models had been able to do. Venkatesh et al. developed the UTAUT model on the basis of integration of eight dominant theoretical models in the area of technology acceptance (see Figure 2) [48]. The UTAUT model includes four core antecedents (i.e. performance expectancy, effort expectancy, social influence, and facilitating conditions) of behavioural intention and actual use behaviour. While gender, experience, age, and voluntariness have been constructed as the four moderators to the main relationships (see Figure 3 ) [48].

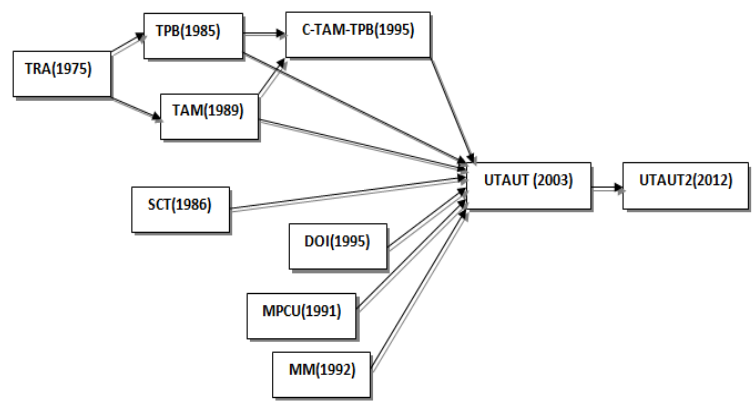

Figure 2. Development of Unified Theory of

Acceptance and Use of Technology Model

Since its inception, the relationships of the UTAUT model have been extensively investigated and confirmed in the context of e-government services $[5,12,49]$. Thus, the UTAUT is suitable to understand the acceptance behaviour of the cloud services in the e-government context. Venkatesh et al. (2012) proposed the UTAUT2 model as an extension to UTAUT model in the context consumer of technology acceptance and use [50]. Since citizens are the main consumers of e-government cloudbased services, the UTAUT2 can serve the aims of this study appropriately [51]. Furthermore, compared to the original theoretical models, UTAUT2 is able to account for a high percentage with respect to explained variance (R2) up to $74 \%$ in behavioural intention (BI) to use IT, which is more effective than any known individual model from the past. However, the unified theory (UTAUT/UTAUT2) tend to be criticized as it does not take into consideration the trust and security concerns which represent two of the specific constructs relevant to e-government context [4]. 


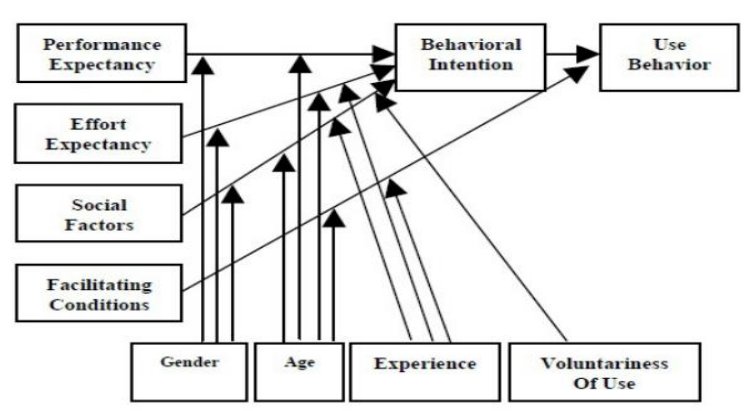

Figure 3. UTAUT [48]

\section{Research Methodology}

In this study, quantitative research methodology employing online questionnaire survey was undertaken to collect the primary data and to meet the aims of the research. A survey questionnaire was selected as it is less time-consuming, inexpensive, the anonymity of respondents can be assured, and it has the ability to provide a data inflow from a large sample with a minimum level of researcher bias [52]. A pre-test was conducted after the questionnaire initially designed by some of the Jordanian public, $\mathrm{PhD}$ researchers, and academic staff. This is important to enhance the questions and check the comprehension of participants before the actual survey is distributed [53]. This resulted in some modifications to the wording of few questions to make it as explicit as possible. The questionnaire was utilized to determine the strength of Jordanian citizens' perceptions of challenges facing the acceptance of cloud-based e-government services and the influence of these challenges on the perceived security. In addition, the same challenges were examined from the perspective of services providers. IT-staff in this study representing a significant pillar of the public sector so it is necessary to explore the views of IT-experts regarding this issue.

As cloud computing $\mathrm{CC}$ is an almost new concept in the developing countries, the researchers provided a definition of this innovative IT on the first page of the online survey. The online questionnaire link was advertised to the targeted sample of the study using different communication channels (e.g. social media groups, personal emails and universities mailing lists). In general, the research sample can be classified as Jordanian citizens who are web users and have a fundamental understanding of egovernment services and CC. The second sample of IT-employees such as web designers, software/system engineers, and programmers, respondents were approached for responding through their personal contacts (i.e. emails) if they had personal experience of the e-government services.

The survey consists of four sections. These are: (1) the respondents' general information (demographic);
(2) the respondents' perceptions regarding barriers and challenges facing acceptance of cloud-based government services; (3) the respondents' perceptions regarding the security of cloud-based public services; (4) the respondents' experience in egovernment and internet use. The survey was conducted based on the University of Bradford human research ethics.

\section{Data Analysis and Findings}

The next sections highlight the key findings and present indications to the answer of the research question drawing on the survey findings. An overview of the online survey questionnaire was provided in the first section. Then, an illustration of the implications of the study question with more details was provided in the following three sections.

\subsection{Overview of the Online Survey Questionnaire:}

As delineated above, the online questionnaire consists of four parts which was presented in Arabic for easier and better understanding of its questions as Arabic is the native spoken language for citizens in Jordan. However, the English survey questionnaire was also built for the purpose of the research. The participation in the questionnaire was completely voluntarily and informed consent was secured through the first question on the cover information sheet indicating that consent is explicit by the "yes" answer to the question.

The survey questionnaire was available to be accessed through the online surveys' website eSurveyCreator.com. It was open "online" for one month to all Jordanians' people around the world. By the end of that time, 243 responses were received. The sample of this study consists of two categories IT staff and Jordanian citizens. 56 participants were employees from different government agencies in Jordan while 187 were ordinary Jordanian citizens. However, 23 citizens' responses were discarded because of incorrect or missing answers. In consequent, a total of 220 responses were valid for the process of data analysis, for identifying the extent in which the e-government challenges influence the acceptance of cloud services in the public sector from Jordanian's people perspective and its impact on the perceived security.

People who understood the cloud services (e.g. IT-staff in the public sector, ICT sector employees, university students) considered as a qualified sample. The reason behind this selection is that they are among the adult's population whom the use of internet become a vital part of their daily life and has the essential knowledge about Cloud Computing services. In addition to IT-staff experience in 
developing and providing such services. Moreover, since the development of Cloud-based services in Jordan is in the initial stage, the respondents will be the main potential adopters. Thus, knowing their perceptions and attitudes is critical to improving the cloud-based e-government services. The analysis results are detailed below.

\subsection{General Information (Demographic)}

The demographic profile of the of the two distinct samples (i.e. Jordanian citizens' and IT-staff) is summarized in Table 2 and Table 3. In this survey, only selected profiles which are gender, age, education level, residency country, internet knowledge level, security awareness level were listed by the authors. Data provided evidence that about two thirds $(66 \%)$ of respondents were male and one third (34\%) female. The bias towards male is owing to that Jordan is one of the developing countries that touted as a male-dominated society where the majority of female's life is at the authority and mercy their male's relatives, this could influence different aspects such as conducting government transactions and employment in the public sector.

In terms of age, the findings revealed that the largest percentage of the general population sample were aged mainly between (21-40) years old, consistent with the largest majority of Jordanian internet users. Most of the respondents hold a bachelor degree as education qualification level which comes in agreement with the general distribution of internet users in Jordan. $78 \%$ of citizens' respondents are from Jordan or other developing countries, while $22 \%$ are from developing countries like the United Kingdom and the USA. In general, the citizens' respondents were self-identified as having medium internet knowledge and beginner to medium security awareness. By comparison, the main difference in the IT-staff sample was self-identification as having a relatively advanced internet knowledge and security awareness.

Table 2. General Information (Demographic) for ITStaff in Public sector

\begin{tabular}{|c|c|c|}
\hline Characteristics & Percentage (\%) & Number \\
\hline Gender & & \\
\hline Male & $69 \%$ & 38 \\
\hline Female & $31 \%$ & 18 \\
\hline Age & & \\
\hline $21-30$ & $41 \%$ & 23 \\
\hline $31-40$ & $54 \%$ & 30 \\
\hline $41-50$ & $5 \%$ & 3 \\
\hline Education Level & & \\
\hline Diploma & $25 \%$ & 14 \\
\hline Bachelor & $66 \%$ & 37 \\
\hline Postgraduate & $9 \%$ & 5 \\
\hline Residency Country & & \\
\hline Jordan or developing & $100 \%$ & 56 \\
\hline
\end{tabular}

\begin{tabular}{|c|c|c|}
\hline countries & \multicolumn{2}{|l|}{} \\
\hline $\begin{array}{l}\text { Internet Knowledge } \\
\text { Level }\end{array}$ & \multicolumn{2}{|l|}{} \\
\hline Advanced & $100 \%$ & 56 \\
\hline $\begin{array}{l}\text { Security Awareness } \\
\text { Level }\end{array}$ & & \\
\hline Medium & $73 \%$ & 41 \\
\hline Advanced & $27 \%$ & 15 \\
\hline
\end{tabular}

Table 3. General Information (Demographic) for Jordanian Citizens

\begin{tabular}{|c|c|c|}
\hline Characteristics & Percentage $(\%)$ & Number \\
\hline \multicolumn{3}{|l|}{ Gender } \\
\hline Male & $66 \%$ & 108 \\
\hline Female & $34 \%$ & 56 \\
\hline \multicolumn{3}{|l|}{ Age } \\
\hline $18-20$ & $3 \%$ & 5 \\
\hline $21-30$ & $68 \%$ & 112 \\
\hline $31-40$ & $16 \%$ & 26 \\
\hline $41-50$ & $11 \%$ & 18 \\
\hline $50+$ & $2 \%$ & 3 \\
\hline \multicolumn{3}{|l|}{ Education Level } \\
\hline $\begin{array}{lll}\begin{array}{l}\text { Secondary } \\
\text { below }\end{array} & \text { School or } \\
\end{array}$ & $7 \%$ & 12 \\
\hline Diploma & $8 \%$ & 13 \\
\hline Bachelor & $63 \%$ & 103 \\
\hline Postgraduate & $22 \%$ & 36 \\
\hline \multicolumn{3}{|l|}{ Residency Country } \\
\hline $\begin{array}{l}\text { Jordan or developing } \\
\text { countries }\end{array}$ & $78 \%$ & 128 \\
\hline Developed countries & $22 \%$ & 36 \\
\hline \multicolumn{3}{|l|}{$\begin{array}{l}\text { Internet } \\
\text { Level }\end{array}$} \\
\hline Beginner & $2 \%$ & 4 \\
\hline Medium & $60 \%$ & 98 \\
\hline Advanced & $38 \%$ & 62 \\
\hline \multicolumn{3}{|l|}{$\begin{array}{l}\text { Security Awareness } \\
\text { Level }\end{array}$} \\
\hline Beginner & $57 \%$ & 93 \\
\hline Medium & $32 \%$ & 53 \\
\hline Advanced & $11 \%$ & 18 \\
\hline
\end{tabular}

This overview of the general demographic profile of the participants will help in the results' interpretation and provide the answer to the research question in the next sections.

\subsection{Challenges to Cloud-Based E- Government services Acceptance: Interpretation of the study Question}

According to the results, there are a number of challenges and barriers of e-government acceptance and adoption, which are: technological, humanaspects, social, and financial that are still obstruct the acceptance and use of cloud computing services in Jordanian public sector from the participants' perspective (see Figure 4). A number of authors indicated that the diffusion of innovative technologies (e.g. e-government services) into citizens and societies is not without challenges. However, the government sector faces barriers from citizens who expect higher standards of the public 
services (i.e. governmental) than from services of the private sector. Nine barriers have been identified to acceptance of e-government services by the researchers based on literature review.

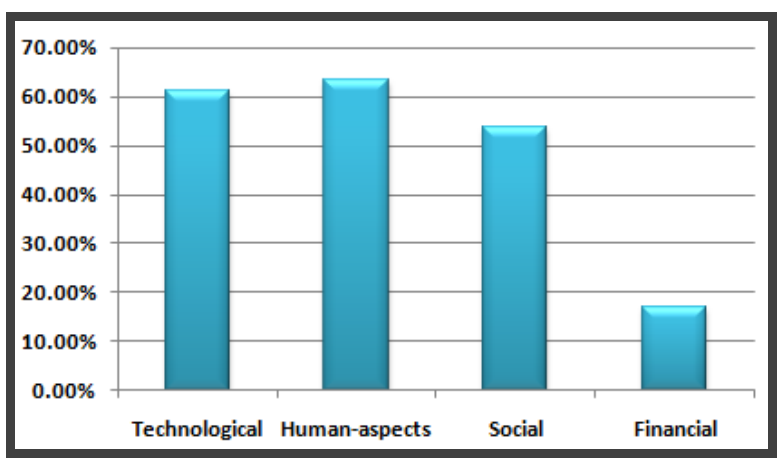

Figure 4. Challenges of Cloud Computing in the Public Sector

In consequent, respondents were asked for evaluating their perception of the importance level for each barrier by considering the challenges if it does not represent one (0), important one (1), or very important one (2).

7.3.1. Citizens' Perceptions Regarding Barriers of Cloud-Based E-Government services. Tables 4 and 5 shows all the nine barriers were chosen as either very important or important barrier and no one of the nine was chosen as not a challenge from all participants.

Table 4. Very Important Barriers to Accept CloudBased Services from Citizens' Perspectives

\begin{tabular}{|l|l|l|c|}
\hline No & Barrier & $\begin{array}{l}\text { Very } \\
\text { Barrier }\end{array}$ & Important \\
\hline \multicolumn{2}{|l|}{} & Number & Percent \% \\
\hline 1 & IT infrastructure & 85 & $51.8 \%$ \\
\hline 2 & Security & 142 & $86.6 \%$ \\
\hline 3 & Availability & 52 & $31.7 \%$ \\
\hline 4 & Accessibility & 62 & $37.8 \%$ \\
\hline 5 & Website design & 78 & $47.5 \%$ \\
\hline 6 & Lack of awareness & 144 & $87.8 \%$ \\
\hline 7 & IT skills & 55 & $33.5 \%$ \\
\hline 8 & Culture & 117 & $71.3 \%$ \\
\hline 9 & $\begin{array}{l}\text { Lack of budget / } \\
\text { high cost }\end{array}$ & 41 & $25 \%$ \\
\hline
\end{tabular}

Table 5. Important Barriers to Accept Cloud-Based Services from Citizens' Perspectives

\begin{tabular}{|l|l|l|c|}
\hline No & Barrier & \multicolumn{2}{|c|}{ Important Barrier } \\
\hline \multicolumn{2}{|l|}{} & Number & Percent \% \\
\hline 1 & IT infrastructure & 79 & $48.2 \%$ \\
\hline 2 & Security & 22 & $13.4 \%$ \\
\hline 3 & Availability & 112 & $68.3 \%$ \\
\hline 4 & Accessibility & 102 & $62.2 \%$ \\
\hline 5 & Website design & 86 & $52.5 \%$ \\
\hline 6 & Lack of awareness & 20 & $12.2 \%$ \\
\hline
\end{tabular}

\begin{tabular}{|l|l|l|c|}
\hline 7 & IT skills & 109 & $66.5 \%$ \\
\hline 8 & Culture & 47 & $28.7 \%$ \\
\hline 9 & $\begin{array}{l}\text { Lack of budget / } \\
\text { high cost }\end{array}$ & 123 & $75 \%$ \\
\hline
\end{tabular}

7.3.2 IT-Employees' Perceptions Regarding Barriers of Cloud-Based E-Government services. The analysis of the IT-employees' viewpoint about the barriers at the two perceptions levels is summarized in Tables 6 and 7. Again, Lack of awareness and security are the two most popular challenges as illustrated in the next subsection.

Table 6. Very Important Barriers to Accept CloudBased Services from IT-Staff Perspectives

\begin{tabular}{|c|c|c|c|}
\hline No & Barrier & \multicolumn{2}{|l|}{$\begin{array}{l}\text { Very } \\
\text { Barrier }\end{array}$} \\
\hline & & Number & Percent \% \\
\hline 1 & IT infrastructure & 45 & $80.3 \%$ \\
\hline 2 & Security & 46 & $82.1 \%$ \\
\hline 3 & Availability & 35 & $62.5 \%$ \\
\hline 4 & Accessibility & 39 & $69.6 \%$ \\
\hline 5 & Website design & 38 & $67.8 \%$ \\
\hline 6 & Lack of awareness & 53 & $94.6 \%$ \\
\hline 7 & IT skills & 25 & $44.6 \%$ \\
\hline 8 & Culture & 42 & $75 \%$ \\
\hline 9 & $\begin{array}{l}\text { Lack of budget / } \\
\text { high cost }\end{array}$ & 18 & $32.1 \%$ \\
\hline
\end{tabular}

Table 7. Important Barriers to Accept Cloud-Based Services from IT-Staff Perspectives

\begin{tabular}{|l|l|l|c|}
\hline No & Barrier & \multicolumn{2}{l|}{ Important Barrier } \\
\hline \multicolumn{2}{|l|}{} & Number & Percent \% \\
\hline 1 & IT infrastructure & 11 & $19.7 \%$ \\
\hline 2 & Security & 10 & $17.9 \%$ \\
\hline 3 & Availability & 21 & $37.5 \%$ \\
\hline 4 & Accessibility & 17 & $30.4 \%$ \\
\hline 5 & Website design & 18 & $32.2 \%$ \\
\hline 6 & Lack of awareness & 3 & $5.4 \%$ \\
\hline 7 & IT skills & 31 & 55.4 \\
\hline 8 & Culture & 14 & $25 \%$ \\
\hline 9 & $\begin{array}{l}\text { Lack of budget / } \\
\text { high cost }\end{array}$ & 38 & 67.9 \\
\hline
\end{tabular}

7.3.3. Respondents' Perceptions Regarding the "Very Important" Barriers. Inspecting the highest two barriers that citizens and IT employees perceived as being "very important" it can be noticed that the lack of awareness about the cloud-based services and its benefits in the e-government context was popular at $(87.8 \%)$ and $(94.6 \%)$, respectively. This indicates that promotional programs are likely to be an important factor for the success of e-government initiatives [54].

For any latest technology (e.g. cloud services for the public sector) there a number of steps that could help in convincing and encouraging people to accept it first then use it. Research into adoption and use of cloud-based services shows that potential users 
required to perceive that it is easy and convenient to use, useful, and it offer a relative advantage compared to the current ways of performing the things (shin 2013). For citizens and other stakeholders to develop such perceptions before obtaining extensive experience, promotional activities and advertising will contribute significantly to accomplish this aim.

Security concerns of information and services provided by e-government systems come as a second "very important" barrier with a popularity of (86.6\%) and $(82.1 \%)$. There is a consensus among researchers that it is a serious technical barrier and it is also a well-documented perspective for the implementation of e-government services worldwide [14, 26, 55].

7.3.4. Comparison of Barriers Perceptions. This section aims to compare the main standpoints of Jordanian citizens and IT-employees regarding the barriers to accept and use of cloud-based egovernment services. It is evident from the previous sub-sections that there are a number of perceived challenges that are common between both. Firstly, for both of sample categories, the lack of awareness about the cloud-based public services and its benefits as "very important" challenge and ranked it as the most significant one in the list. This consensus between both sample categories indicates that it is a crucial obstacle to be resolved, taking into consideration a high-level of priority.

Next, both of sample populations agreed that Security of public services was identified as the second important barrier in the list of "very important". At last, there was a difference in the next most significant "very important" challenge to the cloud-based e-government acceptance, this reflects the individuals' perspective of sample categories. For the IT-staff within the government agencies, the weakness of the IT infrastructure was viewed as the following ranked barrier as that enable them to provide effective public services. With respect to the ordinary citizens' perspectives, society culture impacts the successful use of innovative government services. Table 8 presents a summary of the common and distinct barriers with their rank according to their popularity percentage.

Table 8. Common and Different Barriers Between the Sample Categories

\begin{tabular}{|l|l|l|l|}
\hline \multirow{2}{*}{ Rank } & \multirow{2}{*}{ Barriers } & \multicolumn{2}{|c|}{ Percentage } \\
\cline { 3 - 4 } & & $\begin{array}{c}\text { IT- } \\
\text { Employees }\end{array}$ & Citizens \\
\hline 1 & Lack of awareness & $94.6 \%$ & $87.8 \%$ \\
\hline 2 & Security & $82.1 \%$ & $86.6 \%$ \\
\hline $3 / 4$ & IT infrastructure & $80.3 \%$ & $51.8 \%$ \\
\hline $4 / 3$ & Culture & $75 \%$ & $71.3 \%$ \\
\hline
\end{tabular}

\subsection{Security Perceptions of Cloud-Based E- Government Services}

Seven of the e-government barriers in the survey affect the security perceptions of the respondents (i.e. citizens and IT employees) towards the acceptance and use of cloud services. It is clear from Table 9 that there is agreement on the ranking of these barriers from the viewpoints of the sample both sides. These were ranked based on the responses percentage which either indicates strongly agree or agree.

Table 9. Perceived Security Barriers To Accept Cloud-Based Services in the E-Government Context

\begin{tabular}{|c|c|c|c|}
\hline \multirow[t]{2}{*}{ Rank } & \multirow[t]{2}{*}{ Barrier } & \multicolumn{2}{|c|}{ Agreement } \\
\hline & & Citizens & $\begin{array}{c}\text { IT } \\
\text { employees }\end{array}$ \\
\hline 1 & $\begin{array}{l}\text { High level of security } \\
\text { concerns regarding "cloud- } \\
\text { based e-government" } \\
\text { services are inspired by } \\
\text { non-technical aspects (e.g. } \\
\text { culture and awareness) }\end{array}$ & $83.6 \%$ & $90.3 \%$ \\
\hline 2 & $\begin{array}{l}\text { Social relations and culture } \\
\text { have a significant influence } \\
\text { on the security of "cloud- } \\
\text { based e-government" } \\
\text { services }\end{array}$ & $81.1 \%$ & $89.2 \%$ \\
\hline 3 & $\begin{array}{l}\text { Lack of security awareness } \\
\text { is one of the main } \\
\text { determinants of the user's } \\
\text { perception regarding the } \\
\text { security of "cloud-based e- } \\
\text { government" services. }\end{array}$ & $76.3 \%$ & $89.1 \%$ \\
\hline 4 & $\begin{array}{l}\text { Perceived security is a } \\
\text { significant resource for } \\
\text { public users' trust of } \\
\text { "cloud-based } \\
\text { government" services. }\end{array}$ & $70.6 \%$ & $85 \%$ \\
\hline 5 & $\begin{array}{l}\text { The design of the "cloud- } \\
\text { based e-government" } \\
\text { website influence the user } \\
\text { perception of its security }\end{array}$ & $60.1 \%$ & $67.4 \%$ \\
\hline 6 & $\begin{array}{l}\text { There is a lack of security } \\
\text { guidelines for using } \\
\text { "cloud-based } \\
\text { government" services, on } \\
\text { the government website, } \\
\text { social media or other } \\
\text { media channels. }\end{array}$ & $56.8 \%$ & $62.8 \%$ \\
\hline 7 & $\begin{array}{l}\text { There is a lack of } \\
\text { regulations and policies to } \\
\text { use cloud public services. }\end{array}$ & $44.9 \%$ & $59.3 \%$ \\
\hline
\end{tabular}

For the barriers that the two study samples perceived as a security challenge associated with acceptance and adoption of cloud-based egovernment, it is clear that the non-technical aspects such as culture and awareness got the highest rank at $(83.6 \%)$ and $(90.3 \%)$ respectively (see Figures 5 and $6)$. Thus, the main attention should be paid to these areas by the services provider (i.e. government). 


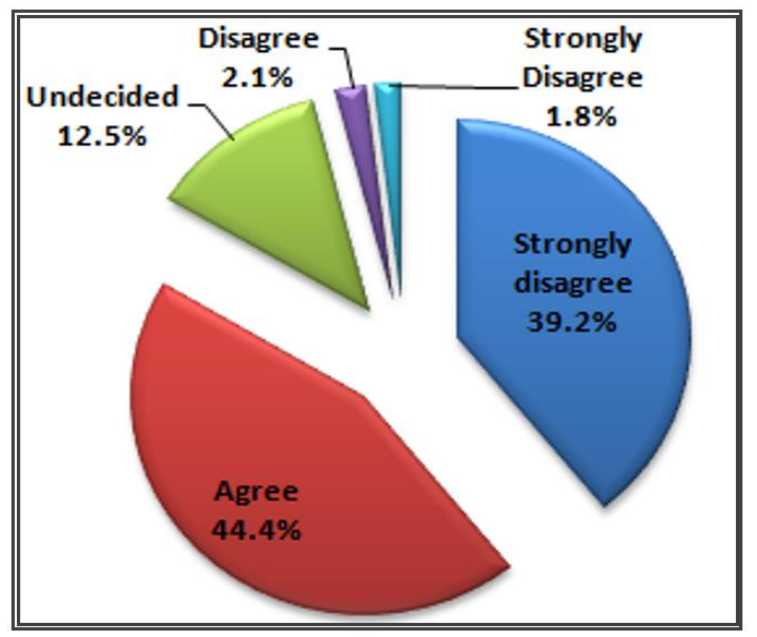

Figure 5. Non-Technical Security Barriers from Citizens Perspective

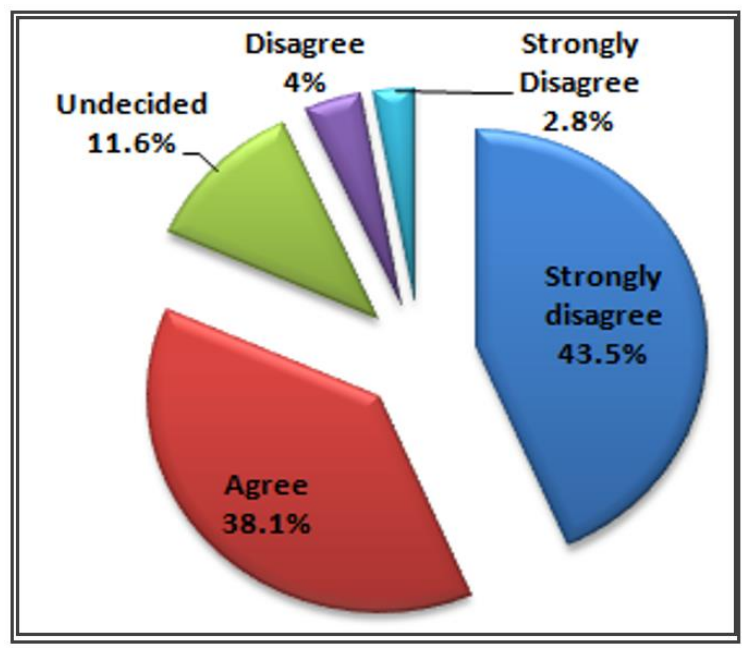

Figure 6. Non-Technical Security Barriers from IT Employees Perspective

The implementation of innovative e-government services faces the challenge of cultural inertia which required to be overcome, particularly in developing countries [35]. The cultural issues have a different influence between developed and developing nations. To give an illustration, the survey findings revealed that more than $(64 \%)$ of the citizens' sample who live in developed countries prefer to conduct online transactions compared to about (35\%) of those in Jordan and other developing countries (see Figure 7 ). The answers indicated that the main reason is cultural differences, one of the respondents who live in Jordan stated: "I heard about many people who their money was stolen when they try to buy online" while a second commented: " electronic transactions is not guaranteed I prefer to contact the other persons face to face and have a chance of discussion".
Furthermore, culture is still deemed to be as one of the barriers in dealing with the perceived security of cloud-based e-government services $(81.1 \%)$ and $(89.2 \%)$ respectively. Accordingly, it is imperative to educate and train ordinary citizens to build an improved culture regarding the benefits, importance, security of online transactions, particularly cloud services for government sector using a number of promotional ways.

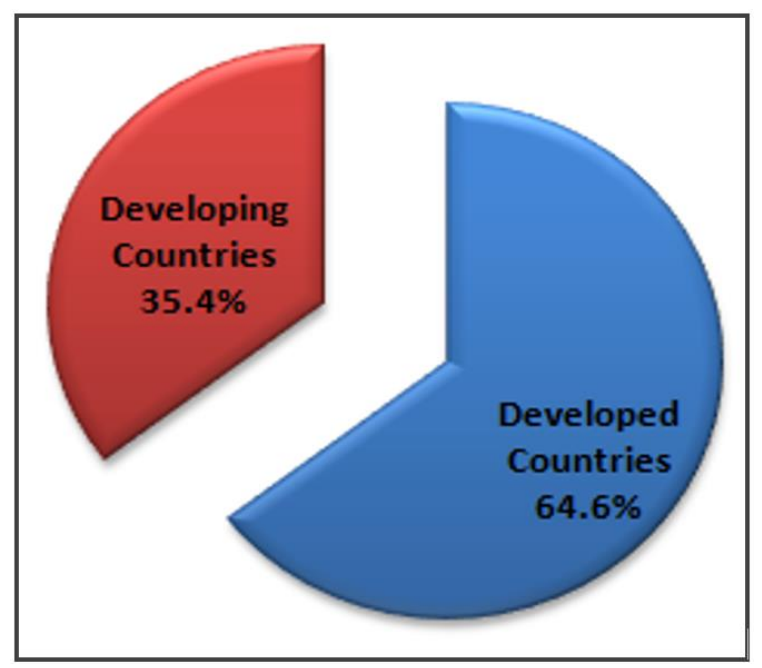

Figure 7. Preference to Use Online Transactions

\section{Conclusion and Future Work}

E-government systems based on cloud technology are the current direction in online services and information around the globe. Government agencies, particularly those in developing countries who aspire to enhance egovernment, can refer to these study findings to promote and design their services. For instance, they can design various promotional programmes and activities for various users.

It is recommended to invest money in a widespread and attractive awareness campaign to encourage citizens effectively to accept and use cloud services. Additionally, people who use cloudservices to conduct governmental transactions would have a discount in terms of the transactions fees. This will help to raise the usage rates, mainly for those who still refuse the use of the e-government services, in general, owing to a number of concerns such as security and trust. The main aim of this paper is to focus on the e-government challenges and how it influences the acceptance of the cloud-based services within the public sector context and to what extent these challenges affect the perceived security.

The findings of this research effort were based on the responses IT staff in the public sector and Jordanian citizens to the research question. This was conducted for supporting the process of decision- 
making by the stakeholders of e-government, and to improve the outcomes of the cloud-based egovernment services provided for the Jordanian society. The challenges were identified based on a relevant literature review and examined through carrying out a survey. The findings of the survey confirmed that security concerns play a significant role in the acceptance and use of cloud services in the government context (second rank). In addition, it revealed that the non-technical aspects have a notable importance among the other security issues in the study context. In consequent, considering these challenges and incorporating them with IT/IS acceptance model is needed for future research work. Owing to its high explanatory power comparing to the previous theories and models of technology acceptance and also its suitability to e-government cloud-based services, the UTAUT2 model would be superior selection providing the base for the future proposed theoretical model addressing the acceptance of such services.

\section{Acknowledgements}

The authors would like to thank Mutah University - Jordan, for the financial support of this research

\section{References}

[1] E. Abu-Shanab, "Antecedents of trust in e-government services: an empirical test in Jordan," Transforming Government: People, Process and Policy, vol. 8, no. 4, pp. 480-499, 2014

[2] A. T. Al-Zyadat, "E Government Systems And Its Impact On Quality Of Service At Public Hospitals In Amman (FILED STUDY)," International Journal of Management (IJM), vol. Volume 7, Issue 6, SeptemberOctober 2016, pp.01-05, 2016.

[3] O. Al-Hujran, M. M. Al-Debei, A. Chatfield, and M. Migdadi, "The imperative of influencing citizen attitude toward e-government adoption and use," Computers in human Behavior, vol. 53, pp. 189-203, 2015.

[4] Y. K. Dwivedi, N. P. Rana, M. Janssen, B. Lal, M. D. Williams, and M. Clement, "An empirical validation of a unified model of electronic government adoption (UMEGA)," Government Information Quarterly, 2017.

[5] Y.-S. Wang and Y.-W. Shih, "Why do people use information kiosks? A validation of the Unified Theory of Acceptance and Use of Technology," Government Information Quarterly, vol. 26, no. 1, pp. 158-165, 2009.

[6] Y. K. Dwivedi and N. Mustafee, "It's unwritten in the Cloud: the technology enablers for realising the promise of Cloud Computing," Journal of Enterprise Information Management, vol. 23, no. 6, pp. 673-679, 2010.
[7] S. Paquette, P. T. Jaeger, and S. C. Wilson, "Identifying the security risks associated with governmental use of cloud computing," Government Information Quarterly, vol. 27 , no. 3, pp. 245-253, 2010.

[8] T. Almarabeh, Y. K. Majdalawi, and H. Mohammad, "Cloud Computing of E-Government," ed: Communications and Network, 2016, 8, 1- 8, 2016.

[9] D. C. Wyld, "The cloudy future of government IT: Cloud computing and the public sector around the world," International Journal of Web \& Semantic Technology, vol. 1, no. 1, pp. 1-20, 2010.

[10] N. N. Almutairi and S. F. Thuwaini, "Cloud Computing Uses for E-Government in the Middle East Region Opportunities and Challenges," International Journal of Business and Management, vol. 10, no. 4, p. 60, 2015

[11] Microsoft. (2014, 30/6/2017). Microsoft in Government: Customer Stories (The Hashemite Kingdom of Jordan) August 15, 2014. Available: https://enterprise.microsoft.com/en-us/customer-story/ industries/government/the-hashemite-kingdom-of-jordan/

[12] V. Weerakkody, R. El-Haddadeh, F. Al-Sobhi, M. A. Shareef, and Y. K. Dwivedi, "Examining the influence of intermediaries in facilitating e-government adoption: An empirical investigation," International Journal of Information Management, vol. 33, no. 5, pp. 716-725, 2013/10/01/ 2013

[13] H. Al-Rashidi, "The role of internal stakeholders and influencing factors during the phases of e-government initiative implementation," 2013.

[14] D. Belanche-Gracia, L. V. Casalo-Arino, and A. Pérez-Rueda, "Determinants of multi-service smartcard success for smart cities development: A study based on citizens' privacy and security perceptions," Government information quarterly, vol. 32, no. 2, pp. 154-163, 2015.

[15] A. Savoldelli, C. Codagnone, and G. Misuraca, "Understanding the e-government paradox: Learning from literature and practice on barriers to adoption," Government Information Quarterly, vol. 31, pp. S63-S71, 2014.

[16] Z. Ebrahim and Z. Irani, "E-government adoption: architecture and barriers," Business process management journal, vol. 11, no. 5, pp. 589-611, 2005.

[17] T. Almarabeh and A. AbuAli, "A general framework for e-government: definition maturity challenges, opportunities, and success," European Journal of Scientific Research, vol. 39, no. 1, pp. 29-42, 2010.

[18] V. Ndou, "E-government for developing countries: opportunities and challenges," The electronic journal of information systems in developing countries, vol. 18, 2004.

[19] H. R. Nemati, Information Security and Ethics: Concepts, Methodologies, Tools, and Applications (no. 
Book, Whole). US: Information Science Reference (Isr), 2008.

[20] R. K. Chellappa and P. A. Pavlou, "Perceived information security, financial liability and consumer trust in electronic commerce transactions," Logistics Information Management, vol. 15, no. 5/6, pp. 358-368, 2002.

[21] S. Alateyah, R. M. Crowder, and G. B. Wills, "Citizen adoption of E-government services," in International Conference on Information Society (i-Society 2012), 2012, pp. 182-187: IEEE.

[22] M. Alomari, P. Woods, and K. Sandhu, "Predictors for e-government adoption in Jordan: Deployment of an empirical evaluation based on a citizen-centric approach," Information Technology \& People, vol. 25, no. 2, pp. 207 234, 2012.

[23] J. I. Criado and M. C. Ramilo, "E-government in practice: an analysis of Web site orientation to the citizens in Spanish municipalities," (in English), International Journal of Public Sector Management, vol. 16, no. 3, pp. 191-218, 00, 20032016-09-27 2003.

[24] M. Rehman and V. Esichaikul, "Factors influencing the adoption of e-government in Pakistan," in E -Business and $\mathrm{E}$-Government (ICEE), International Conference, $\mathrm{pp}$. 1-4, 2011, pp. 1-4: IEEE.

[25] S. A. Alateyah, R. M. Crowder, and G. B. Wills, "Identified factors affecting the citizen's intention to adopt e-government in saudi arabia," 2013, p. 904: World Academy of Science, Engineering and Technology (WASET).

[26] S. Sang, J.-D. Lee, and J. Lee, "E-Government challenges in least developed countries (LDCs): a case of Cambodia," 2009, vol. 3, pp. 2169-2175: IEEE.

[27] A. Dugdale, A. Daly, F. Papandrea, and M. Maley, "Accessing e-government: challenges for citizens and organizations," International Review of Administrative Sciences, vol. 71, no. 1, pp. 109-118, 2005.

[28] V. Weerakkody, R. El-Haddadeh, and S. Al-Shafi, "Exploring the complexities of e-government implementation and diffusion in a developing country: Some lessons from the State of Qatar," Journal of Enterprise Information Management, vol. 24, no. 2, pp. 172-196, 2011.

[29] N. P. Rana, Y. K. Dwivedi, and M. D. Williams, "Analysing challenges, barriers and CSF of egov adoption," Transforming Government: People, Process and Policy, vol. 7, no. 2, pp. 177-198, 2013.

[30] A. M. Odat, "E-Government In Developing Countries: Framework Of Challenges And Opportunities," Journal of Theoretical and Applied Information Technology, vol. Vol. 46 No.2, pp. 1013-1021, 2012.

[31] S. Furnell and L. Moore, "Security literacy: the missing link in today's online society?," Computer Fraud \& Security, vol. 2014, no. 5, pp. 12-18, 5// 2014.
[32] M. E. Alzahrani and R. D. Goodwin, "Towards a UTAUT-based Model for the Study of EGovernment Citizen Acceptance in Saudi Arabia," World Academy of Science, Engineering and Technology, International Journal of Social, Behavioral, Educational, Economic, Business and Industrial Engineering, vol. 6, no. 4, pp. 376$382,2012$.

[33] K. Roer, Build a security culture. IT Governance Publishing, 2015.

[34] A. Carvin, J. Hill, and S. Smothers, E-government for all: Ensuring equitable access to online government services. The EDC center for media \& community and the NYS Forum, 2004

[35] M. Ali, V. Weerakkody, and R. El-Haddadeh, "The impact of national culture on e-government implementation: A comparison case study," 2009.

[36] P. Mell and T. Grance, "The NIST definition of cloud computing," 2011.

[37] N. Wang, H. Liang, Y. Jia, S. Ge, Y. Xue, and Z. Wang, "Cloud computing research in the IS discipline: A citation/co-citation analysis," Decision Support Systems, vol. 86, pp. 35-47, 2016.

[38] I. Arpaci, "Understanding and predicting students' intention to use mobile cloud storage services," Computers in Human Behavior, vol. 58, pp. 150-157, 2016.

[39] K. K. Smitha, T. Thomas, and K. Chitharanjan, "Cloud Based E-Governance System: A Survey," Procedia Engineering, vol. 38, pp. 3816-3823, 2012/01/01/ 2012.

[40] S. Hashemi, K. Monfaredi, and M. Masdari, "Using cloud computing for e-government: challenges and benefits," International Journal of Computer, Information, Systems and Control Engineering, vol. 7, no. 9, pp. 596603, 2013.

[41] D.-H. Shin, "User centric cloud service model in public sectors: Policy implications of cloud services," Government Information Quarterly, vol. 30, no. 2, pp. 194203, 4// 2013.

[42] O. Ali, J. Soar, J. Yong, H. McClymont, and D. Angus, "Collaborative cloud computing adoption in Australian regional municipal government: An exploratory study," in 19th International Conference on Computer Supported Cooperative Work in Design (CSCWD), 2015, pp. 540-548: IEEE.

[43] M. A. Aveek and M. Rahman, "Implementing egovernance in Bangladesh using cloud computing technology," 2011.

[44] A. Tripathi and B. Parihar, "E-governance challenges and cloud benefits," in IEEE International Conference on Computer Science and Automation Engineering (CSAE), 2011, 2011, vol. 1, pp. 351-354: IEEE.

[45] D. Zissis and D. Lekkas, "Securing e-Government and e-Voting with an open cloud computing architecture," 
Government Information Quarterly, vol. 28, no. 2, pp. 239$251,2011$.

[46] V. Venkatesh, J. Y. L. Thong, and X. Xu, "Unified theory of acceptance and use of technology: a synthesis and the road ahead," 2016.

[47] A. Alkhwaldi and M. Kamala, "Why Do Users Accept Innovative Technologies? A critical review of technology acceptance models and theories," Journal of Multidisciplinary Engineering Science and Technology (JMEST), vol. Vol. 4 Issue 8, August -2017, pp. 79627971, 2017.

[48] V. Venkatesh, M. G. Morris, G. B. Davis, and F. D. Davis, "User acceptance of information technology: Toward a unified view," MIS quarterly, pp. 425-478, 2003.

[49] S. AlAwadhi and A. Morris, "The Use of the UTAUT Model in the Adoption of E-government Services in Kuwait," in Proceedings of the 41st Hawaii International Conference on System Sciences, 2008, pp. 219-219: Ieee.

[50] V. Venkatesh, J. Y. L. Thong, and X. Xu, "Consumer acceptance and use of information technology: extending the unified theory of acceptance and use of technology," 2012.

[51] M. Z. I. Lallmahomed, N. Lallmahomed, and G. M. Lallmahomed, "Factors influencing the adoption of eGovernment services in Mauritius," Telematics and Informatics, vol. 34, no. 4, pp. 57-72, 2017.

[52] D. E. Gray, Doing research in the real world, Third ed. (no. Book, Whole). London: SAGE Publications Ltd, 2014.

[53] M. Saunders, P. Lewis, and A. Thornhill, Research methods for business students, Seventh ed. (no. Book, Whole). Harlow, Essex: Pearson Education Limited, 2016.

[54] M. Ovais Ahmad, J. Markkula, and M. Oivo, "Factors affecting e-government adoption in Pakistan: a citizen's perspective," Transforming Government: People, Process and Policy, vol. 7, no. 2, pp. 225-239, 2013.

[55] J.-W. Lian, "Critical factors for cloud-based e-invoice service adoption in Taiwan: An empirical study," International Journal of Information Management, vol. 35, no. 1, pp. 98-109, 2015. 